\title{
Feasibility of enhanced recovery after surgery in gastric surgery: a retrospective study
}

\author{
Takanobu Yamada ${ }^{1,2^{*}}$, Tsutomu Hayashi ${ }^{1,2}$, Toru Aoyama ${ }^{1,2}$, Junya Shirai ${ }^{1,2}$, Hirohito Fujikawa ${ }^{1,2}$, Haruhiko Cho ${ }^{1}$, \\ Takaki Yoshikawa', Yasushi Rino ${ }^{2}$, Munetaka Masuda ${ }^{2}$, Hideki Taniguchi ${ }^{3}$, Ryoji Fukushima ${ }^{4}$ and Akira Tsuburaya ${ }^{1}$
}

\begin{abstract}
Background: Enhanced recovery after surgery (ERAS) programs have been reported to be feasible and useful for maintaining physiological function and facilitating recovery after colorectal surgery. The feasibility of such programs in gastric surgery remains unclear. This study assessed whether an ERAS program is feasible in patients who undergo gastric surgery.

Methods: The subjects were patients who underwent gastric surgery between June 2009 and February 2011 at the Department of Gastrointestinal Surgery, Kanagawa Cancer Center. They received perioperative care according to an ERAS program. All data were retrieved retrospectively. The primary end point was the incidence of postoperative complications. The secondary end point was postoperative outcomes.

Results: A total of 203 patients were studied. According to the Clavien-Dindo classification, the incidence of $\geq$ grade 2 postoperative complications was $10.8 \%$ and that of $\geq$ grade 3 complications was $3.9 \%$. Nearly all patients did not require delay of meal step-up (95.1\%). Only 6 patients (3.0\%) underwent reoperation. The median postoperative hospital stay was 9 days. Only 4 patients (2.0\%) required readmission. There was no mortality.
\end{abstract}

Conclusions: Our results suggest that our ERAS program is feasible in patients who undergo gastric surgery.

Keywords: Enhanced recovery after surgery, Gastric cancer, Gastrectomy, Feasibility, Postoperative complications

\section{Background}

Gastric cancer is the second leading cause of cancerrelated death worldwide [1]. Complete surgical resection plays the most important role in the cure of gastric cancer; however, surgery for gastric cancer remains a highrisk procedure with clinically significant postoperative stress, complications, and sequelae. Morbidity and mortality from radical gastrectomy range from 9.1-46.0\% and $0-13 \%$, respectively [2-7].

Enhanced recovery after surgery (ERAS) programs have been proposed to maintain physiological function and facilitate postoperative recovery [8]. In the following studies, ERAS was considered to reduce rates of morbidity, shorten length of hospital stay [9-11]. ERAS programs have many elements, including preoperative education, preoperative carbohydrate loading, omission of bowel preparation,

\footnotetext{
* Correspondence: takay0218@yahoo.co.jp

'Department of Gastrointestinal Surgery, Kanagawa Cancer Center, 1-1-2 Nakao, Asahi, 241-0815 Yokohama, Kanagawa, Japan

${ }^{2}$ Department of Surgery, Yokohama City University, Yokohama, Japan

Full list of author information is available at the end of the article
}

epidural analgesia without opioids, early postoperative enteral feeding, early mobilization of patients, and thrombotic prophylaxis. In colorectal surgery, several studies have reported that ERAS programs are feasible and useful [9-11].

We previously demonstrated that an ERAS protocol is useful in patients who undergo elective radical gastrectomy [12]. Other studies have reported that ERAS programs or fast-track surgery in gastric surgery can accelerate postoperative rehabilitation [13-18]. However, the number of patients assessed in these studies was small. In addition, some studies found that the incidence of some postoperative complications, especially nausea, vomiting, and postoperative ileus, tended to be higher in the ERAS group than in the conventional group, suggesting that ERAS programs might increase the risk of some complications after gastric surgery. Because of these controversial results, it is necessary to confirm the feasibility of ERAS programs in gastric surgery.

The present study evaluated whether an ERAS program was feasible in more than 200 patients who underwent 
gastric surgery. Emphasis was placed on postoperative gastrointestinal complications.

\section{Methods \\ Patients}

Between June 2009 and February 2011, a total of 256 patients with gastric cancer underwent surgery at the Department of Gastrointestinal Surgery, Kanagawa Cancer Center. The inclusion criteria for this study were (1) a histologically confirmed diagnosis of adenocarcinoma of stomach and (2) the receipt of elective distal gastrectomy or total gastrectomy with lymphadenectomy. We excluded patients who preoperatively received any chemotherapy or radiotherapy. We also excluded patients who underwent proximal gastrectomy or laparoscopy-assisted total gastrectomy because these procedures are not standard in Japan and are mainly used in patients enrolled in clinical trials. These surgeries themselves have not been confirmed safe and feasible yet.

All patients received perioperative care according to our ERAS program. Operations were performed by the same team of surgeons (three specialists and four trainees). In principle, patients with a preoperative diagnosis of stage I disease received laparoscopic surgery with D1+ dissection, and the others received open surgery with D2 dissection [19].

\section{ERAS program}

In their Cochrane review, Spanjersberg et al. regard ERAS protocols as programs that include 7 or more of 17 ERAS items [10]. Our ERAS program included 13 items.

\section{Preoperative}

Preoperative counseling was held in the outpatient clinic before hospitalization and in the ward after admission. Patients could eat a normal diet until dinner of the day before surgery. Magnesium oxide and a New Lecicarbon ${ }^{\circ}$ suppository (Zeria Pharmaceutical Co., Ltd., Tokyo, Japan) were administered on the day before surgery (Table 1).

\section{Perioperative}

Patients, excluding those who had gastric obstruction with decreased output, could drink two 500-ml plastic bottles of $\mathrm{OS}^{-1} 1^{\circ}$ (2.5\% carbohydrate, Otsuka Pharmaceutical, Tokushima, Japan) $3 \mathrm{~h}$ before surgery. Premedication was not administered. Anesthesia consisted of a combination of epidural analgesia (Th 7-11) and general anesthesia. In principle, no drain was used in distal gastrectomy, and one or two drains were used in total gastrectomy. The nasogastric tube was removed immediately after surgery (Table 1 ).

\section{Postoperative}

Day of surgery: A continuous thoracic epidural infusion of analgesics was given for 2 days after surgery. To prevent postoperative pain, a nonsteroidal anti-inflammatory drug (50 mg flurbiprofen axetil) was administered intravenously twice daily after surgery until the resumption of oral intake. Postoperative day (POD) 1: Patients were encouraged to sit out of bed for more than $6 \mathrm{~h}$. POD 2: Oral intake was started with water and a can of oral nutrition supplement $(250 \mathrm{ml}$ Ensure Liquid ", Abbott Japan Co., Ltd., Tokyo, Japan). After the resumption of oral intake, $300 \mathrm{mg}$ of acetaminophen was administered orally three times daily. The patients were encouraged to walk the length of the ward. An antithrombotic agent (enoxaparin sodium 2000 IU twice daily or fondaparinux $2.5 \mathrm{mg}$ daily) was injected for 2 days $6 \mathrm{~h}$ after removal of the epidural catheter. POD 3: The patients started to eat soft food and were stepped up to regular food every 2 days (3 steps). The criteria for discharge were as follows: adequate pain relief, soft diet intake, return to preoperative mobility level, and normal laboratory data on POD 7 (Table 1).

The ERAS program evaluated in the present study was developed by a team of surgeons and anesthesiologists working in close cooperation with a data safety monitoring committee (DSMC). The feasibility and safety audit was completed by the DSMC in September 2009, when 50 patients had been treated according to the ERAS program. Our ERAS program in practice was approved both by the institutional clinical pathway committee and the DSMC. This study, a retrospective analysis, have been performed upon the approval of the institutional review board of Kanagawa Cancer Center. Informed consent for the ERAS program and using the clinical date without identifying personal information were taken before surgery.

\section{Data collection (end points)}

All data were retrieved retrospectively from the patients' database and clinical records. The primary end point was the incidence of postoperative complications. Complications were defined as $\geq$ grade 2 complications according to Clavien-Dindo classification within 30 days after surgery [20]. Secondary end points were postoperative outcomes such as onset of walking, onset of oral intake, onset of flatus, onset of defecation, delay of meal step-up, reoperation, postoperative hospital stay, readmission, and mortality. We delayed meal step-up if the patient ate 40 percent or less of meals for 2 days.

Pathological findings were categorized according to the $7^{\text {th }}$ edition of UICC-TNM [21]. Continuous data are expressed as medians (range).

\section{Results}

A total of 203 patients were studied. 
Table 1 Time table of the modified ERAS program

\begin{tabular}{|c|c|c|c|c|c|c|c|c|}
\hline Operative day & -1 & 0 & +1 & +2 & $+3+4$ & +5 & +6 & +7 \\
\hline Preoperative counseling & \multicolumn{8}{|c|}{ Preoperative counseling was held in the outpatient clinic before hospitalization and in the ward after admission. } \\
\hline Pre-medication & \multicolumn{8}{|c|}{ Patients do not receive any sedation. } \\
\hline Oral intake & $\begin{array}{l}\text { Normal diet until } \\
\text { midnight }\end{array}$ & $\begin{array}{l}\text { Oral hydration solution } \\
\left(\text { OS }-1^{\oplus}\right) 3 \mathrm{~h} \text { before } \\
\text { surgery }\end{array}$ & & $\begin{array}{l}\text { Drink a water and oral } \\
\text { nutrition supplement } \\
\text { (Endure Liquid }^{\oplus} \text { ) }\end{array}$ & \multirow{2}{*}{\multicolumn{4}{|c|}{$\begin{array}{l}\text { Liquid diet ( } 3 \text { steps up to a } \\
\text { soft diet every } 2 \text { days) }\end{array}$}} \\
\hline Bowel preparation & $\begin{array}{l}1 \mathrm{~g} \text { magnesium } \\
\text { oxide and a New } \\
\text { Lecicarbon } \\
\text { suppository }\end{array}$ & & & & & & & \\
\hline \multirow[t]{3}{*}{$\begin{array}{l}\text { Anesthesia and } \\
\text { Analgesics }\end{array}$} & & $\begin{array}{l}\text { Combination of epidural } \\
\text { analgesia (TH7-11) and } \\
\text { general anesthesia during } \\
\text { surgery }\end{array}$ & & & & & & \\
\hline & & $\begin{array}{l}\text { Continuous thoracic } \\
\text { epidural infusion of } \\
\text { analgesics after surgery }\end{array}$ & $\rightarrow$ & $\begin{array}{l}\text { Removing epidural } \\
\text { catheter }\end{array}$ & & & & \\
\hline & & $\begin{array}{l}\text { Nonsteroidal anti-inflammatory } \\
\text { drug intravenously after } \\
\text { surgery twice daily }\end{array}$ & $\rightarrow$ & $\begin{array}{l}\text { Acetoaminophen three } \\
\text { times a daily orally }\end{array}$ & $\rightarrow \rightarrow$ & & & \\
\hline \multirow[t]{2}{*}{ Drain and NGT } & & $\begin{array}{l}\text { No drain in distal gastrectomy, } \\
\text { one or two drains in total } \\
\text { gastrectomy }\end{array}$ & & Removing drain(s) & & & & \\
\hline & & $\begin{array}{l}\text { NGT was removed } \\
\text { immediately after } \\
\text { surgery }\end{array}$ & & & & & & \\
\hline Urinary catheter & & & & Removing & & & & \\
\hline $\mathrm{ADL}$ & & & $\begin{array}{l}\text { Encourage to } \\
\text { sit out of bed } \\
\text { for more than } \\
6 \mathrm{~h}\end{array}$ & $\begin{array}{l}\text { Encourage to walk the } \\
\text { length of the ward }\end{array}$ & $\rightarrow \rightarrow$ & $\rightarrow$ & $\rightarrow$ & $\rightarrow$ \\
\hline Antithromboprophylaxis & & & None & $\begin{array}{l}\text { Subcutaneous injection } \\
\text { of antithrombotic agent } \\
\text { (enoxaparin sodium or } \\
\text { fondaparinux) }\end{array}$ & $\rightarrow \rightarrow$ & None & $\rightarrow$ & $\rightarrow$ \\
\hline X-ray and blood exam. & & $\circ$ & $\circ$ & & & & & $\begin{array}{l}\text { o (Check } \\
\text { discharge } \\
\text { creiteria) }\end{array}$ \\
\hline
\end{tabular}

NGT: Nasogastric tube, ADL: Activity of daily life.

\section{Patients' characteristics}

There were 133 men and 70 women. Ten patients diagnosed non-adenocarcinoma or having other cancer simultaneously, sixteen patients received preoperative chemotherapy, Twenty two patients undergoing laparoscopy-assisted total gastrectomy, four patients undergoing remnant total gastrectomy, and one patient undergoing proximal gastrectomy were excluded. The median age was 67 (32-84) years. Performance status was good in most patients. Mean body mass index (BMI) was 22.2 (16.2-31.4) (Table 2).

\section{Surgical procedures}

Laparoscopic surgery was performed in 76 patients (37.4\%), and total gastrectomy in 60 patients (29.6\%). 83 patients (40.9\%) underwent D2 lymph node dissection. Combined organ resection was performed in 34 patients, among whom 29 (85.3\%) additionally underwent splenectomy (including pancreatico-splenectomy in 1 patient). Billroth I reconstruction was performed in 116 (57.1\%) patients, and Roux-en-Y reconstruction was done in 83 (40.9\%). The median operation time was 179 (80-577) minutes. The estimated median blood loss was 110 (01620) $\mathrm{ml}$ (Table 2).

\section{Pathological characteristics}

Early gastric cancer (T1) was confirmed in 121 patients (59.6\%). 131 patients (64.5\%) had no evidence of lymph node metastasis. Final disease stage was stage I in 128 patients $(63.1 \%)$, stage II in 35 (17.2\%), stage III in 31 (15.3\%), and stage IV in $9(4.4 \%)$ (Table 2$).$

\section{Complications and postoperative course}

Grade 2 or higher complications developed in 23 (11.3\%) patients, and grade 3 or higher complications developed 
Table 2 Clinicopathological features

\begin{tabular}{|c|c|c|c|}
\hline \multirow{2}{*}{\multicolumn{2}{|c|}{$\overline{\text { Age (years old) }}$}} & \multicolumn{2}{|c|}{$\begin{array}{l}\text { Patients } \\
(\mathrm{N}=203)\end{array}$} \\
\hline & & \multicolumn{2}{|c|}{$67(32-84)$} \\
\hline \multirow[t]{2}{*}{ Gender } & Male & 133 & $(65.5 \%)$ \\
\hline & Female & 70 & $(34.5 \%)$ \\
\hline \multicolumn{2}{|l|}{ BMI $(\mathrm{kg} / \mathrm{m} 2)^{*}$} & \multicolumn{2}{|c|}{$22.2(16.2-31.4)$} \\
\hline \multirow[t]{3}{*}{ ECOG-PS } & 0 & 177 & $(87.2 \%)$ \\
\hline & 1 & 26 & $(12.8 \%)$ \\
\hline & 2 & 0 & $(0.0 \%)$ \\
\hline \multirow[t]{3}{*}{ ASA-PS } & । & 99 & $(48.8 \%)$ \\
\hline & $\|$ & 103 & $(50.7 \%)$ \\
\hline & III & 1 & $(0.5 \%)$ \\
\hline \multirow[t]{3}{*}{ Procedure } & Open distal gastrectomy & 67 & $(33.0 \%)$ \\
\hline & $\begin{array}{l}\text { Laparoscopy-assisted } \\
\text { distal gastrectomy }\end{array}$ & 76 & $(37.4 \%)$ \\
\hline & Open total gastrectomy & 60 & $(29.6 \%)$ \\
\hline \multirow[t]{2}{*}{ Lymph node dissection } & $\mathrm{D} 1, \mathrm{D} 1+$ & 120 & $(59.1 \%)$ \\
\hline & D2 & 83 & $(40.9 \%)$ \\
\hline \multirow[t]{3}{*}{ Reconstruction } & Billroth I & 116 & $(57.1 \%)$ \\
\hline & Billroth II & 4 & $(2.0 \%)$ \\
\hline & Roux-en Y & 83 & $(40.9 \%)$ \\
\hline \multirow[t]{2}{*}{ Combined organ resection } & yes & 34 & $(16.7 \%)$ \\
\hline & no & 169 & $(83.3 \%)$ \\
\hline \multicolumn{2}{|l|}{ Operation time $(\min .)^{*}$} & \multicolumn{2}{|c|}{$179(80-577)$} \\
\hline \multicolumn{2}{|l|}{ Bleeding $(\mathrm{ml})^{*}$} & \multicolumn{2}{|c|}{$110(0-1620)$} \\
\hline \multirow[t]{4}{*}{ T categories } & $\mathrm{T} 1$ & 121 & $(59.6 \%)$ \\
\hline & $\mathrm{T} 2$ & 27 & $(13.3 \%)$ \\
\hline & T3 & 19 & $(9.4 \%)$ \\
\hline & T4 & 36 & $(17.7 \%)$ \\
\hline \multirow[t]{4}{*}{$\mathrm{N}$ categories } & No & 131 & $(64.5 \%)$ \\
\hline & N1 & 22 & $(10.8 \%)$ \\
\hline & N2 & 19 & $(9.4 \%)$ \\
\hline & N3 & 31 & $(15.3 \%)$ \\
\hline \multirow[t]{4}{*}{ Stage (UICC TNM 7th) } & । & 128 & $(63.1 \%)$ \\
\hline & $\|$ & 35 & $(17.2 \%)$ \\
\hline & III & 31 & $(15.3 \%)$ \\
\hline & IV & 9 & $(4.4 \%)$ \\
\hline
\end{tabular}

BMI; Body mass index, ECOG-PS; Eastern cooperative oncology group performance status, ASA-PS; American society of anesthesiologists physical status, ${ }^{*}$ median (range).

in 8 (3.9\%). Anastomotic leakage occurred in 3 patients (1.5\%), ileus in 2 patients (1.0\%), and anastomotic stenosis in 2 patients $(1.0 \%)$. The incidence of $\geq$ grade 2 complications in patients who underwent open distal gastrectmy, laparoscopy-assisted distal gastrectomy, or open total gastrectomy were $1.9 \%, 3.4 \%$, or $5.4 \%$ respectively $(\mathrm{p}=0.069)$. The incidence of $\geq$ grade 2 complications in patients who
Table 3 Complications

\begin{tabular}{|c|c|c|}
\hline & Clavien-Di & ssification \\
\hline & $\geq$ grade 2 n (\%) & $\geq$ grade $3 \mathrm{n}(\%)$ \\
\hline Pancreas fistula & $7(3.4 \%)$ & $2(1.0 \%)$ \\
\hline Anastomotic leakage & $3(1.5 \%)$ & $3(1.5 \%)$ \\
\hline Ileus & $2(1.0 \%)$ & $0(0 \%)$ \\
\hline Anastomotic stenosis & $2(1.0 \%)$ & $1(0.5 \%)$ \\
\hline Surgical site infection & $2(1.0 \%)$ & $0(0 \%)$ \\
\hline Obstruction & $1(0.5 \%)$ & $1(0.5 \%)$ \\
\hline Pyothorax & $1(0.5 \%)$ & $1(0.5 \%)$ \\
\hline Bleeding & $1(0.5 \%)$ & $0(0 \%)$ \\
\hline Pleural effusion & $1(0.5 \%)$ & $0(0 \%)$ \\
\hline Cholangitis & $1(0.5 \%)$ & $0(0 \%)$ \\
\hline Ascites & $1(0.5 \%)$ & $0(0 \%)$ \\
\hline Toxicoderma & $1(0.5 \%)$ & $0(0 \%)$ \\
\hline Total & $23(11.3 \%)$ & $8(3.9 \%)$ \\
\hline
\end{tabular}

underwent D1 or D1+ dissection was $5.8 \%$, as compared with $18.1 \%$ in patients who underwent D2 dissection ( $\mathrm{p}=$ 0.010). The median onsets of oral intake, flatus, and defecation were POD 2 (1-5), 2 (0-5), and 4 (2-9), respectively. The step-up schedule for meals was delayed in 10 (4.9\%) patients. Five of these patients $(2.4 \%)$ had inadequate oral caloric or fluid intake because of nausea or vomiting. Reoperation was performed in $6(3.0 \%)$ patients. The reasons for reoperation were leakage of the duodenal stump in 2 patients, leakage of the gastroduodenal anastomosis in 1 , bowel obstruction in 1, anastomotic stenosis in 1 , and pyothorax in 1 . The median postoperative hospital stay was 9 (7-53) days. 4 (2.0\%) patients were readmitted within 30 days after surgery. The reasons for readmission were ascites, fever, poor oral intake, and surgical site infection in 1 patient each. There was no mortality. No patient had postoperative pneumonia or required replacement of a nasogastric tube, with exception of 3 patients who had postoperative ileus (Tables 3 and 4).

Table 4 Postoperative outcomes

\begin{tabular}{lc}
\hline Onset of walk $\left(\mathrm{POD}^{*}\right)$ & $2(1-4)$ \\
Onset of oral intake $\left(\mathrm{POD}^{*}\right)$ & $2(1-5)$ \\
Onset of flatus $\left(\mathrm{POD}^{*}\right)$ & $2(0-5)$ \\
Onset of defecation $\left(\mathrm{POD}^{*}\right)$ & $4(2-9)$ \\
Delay of meal step up $(\mathrm{n}(\%))$ & $10(4.9 \%)$ \\
Complication $\mathrm{CD} \geq$ grade2 $(\mathrm{n}(\%))$ & $23(11.3 \%)$ \\
Reoperation (n(\%)) & $6(3.0 \%)$ \\
Postoperative hospital stay(days) & $9(7-53)$ \\
Readmission (n(\%)) & $4(2.0 \%)$ \\
Mortality $(n(\%))$ & $0(0 \%)$ \\
\hline
\end{tabular}

POD; Post operative day, CD; Clavien-Dindo classification, ${ }^{*}$ median (range). 


\section{Discussion}

This is the first large study to evaluate the feasibility of a comprehensive ERAS program in gastric surgery. In our study, the overall incidence of morbidity (i.e., $\geq$ grade 2 complications) was $10.8 \%$, and the incidence of clinically significant events ( $\geq$ grade 3 complications) was only $3.9 \%$. These results obtained with our ERAS program are good as compared with complication rates of conventional perioperative care group in our previous report (12.0\%) as well as other reported complication rates without ERAS program (10.5-46.0\%) [2-7,12]. Although T1 tumors and D1 dissection were dominant in our study, the morbidity rate in the D2 group (18.1\%) was comparable to that in a large randomized controlled trial performed in Japan (JOCG9501 study, 20.9\%) [5].

Among the many elements of ERAS programs, one of the utmost concerns for surgeons is that early postoperative feeding can induce postoperative ileus or anastomosis leakage. Because of these concerns, oral intake of food was previously not allowed for several days after gastrectomy in Japan [22]. In some European countries, food is also withheld for several postoperative days [23], but this practice is not supported by adequate evidence. In fact, in our study the incidences of postoperative ileus and anastomotic leakage were very low $(1.0 \%$ and $1.5 \%$, respectively), as compared with previous studies (0$12.5 \%$ and $0-4.2 \%$, respectively) [2-7]. The incidences of those in conventional prieoperative care of our hospital ( $0 \%$ and $2 \%$, respectively) were similar with these results [12]. Furthermore, meal step-up did not have to be delayed in nearly all patients (95.1\%), and this is also similar with previous reported our internal control (96.0\%) [12]. Several studies have also demonstrated that early oral feeding is feasible and beneficial in gastric surgery [13-18,24,25], but this point remains controversial. Heslin et al. reported that early enteral feeding was not beneficial after surgery for upper gastrointestinal malignancies [26]. On the other hand, Lewis et al. found in their metaanalysis that keeping patients 'nil by mouth' is without benefit; in contrast, early enteral feeding was suggested to reduce mortality [27]. There were six complications that need reoperation in current study. Among those, possibility of relation between the leakage of the gastroduodenal anastomosis and ERAS program could not be denied. But others seem to be unlikely. Our results and the findings of previous studies suggest that early oral or enteral feeding is at least feasible and does not increase the risk of postoperative ileus or anastomotic leakage.

Our study had several limitations. 1) It was conducted retrospectively in a single hospital, and the analyses and endpoints were not preplanned. 2) Most patients had good performance status. Patients with poor performance status (e.g. Eastern cooperative oncology group performance status $\geq 3$, severe dementia, and swallowing difficulty) could not be treated in our hospital, because we specialize in cancer treatment. These could be selection bias. 3) More than half of the patients had T1 disease and underwent limited lymph node dissection (D1+), whichmight account for the good results of our study. In particular, D2 or more radical lymph node dissection has been repeatedly reported to increase the risk of surgery-related complications [2-5]. Consistent with the previous findings, the incidence of complications was higher after D2 dissection than after D1 dissection in our study. Finally, 4) our ERAS program did not include fluid management, which is one of the key elements of ERAS programs. There was not robust evidence of perioperative fluid management in gastric surgery at the time we introduced ERAS.

\section{Conclusions}

In conclusion, our results suggest that our ERAS program is feasible in at least early-staged and relatively young patients undergoing elective gastric surgery. Further studies, for which population ERAS program can be applied and whether ERAS programs have potential benefits, are necessary.

\section{Abbreviations}

ERAS: Enhanced recovery after surgery; POD: Postoperative day; DSMC: Data safety monitoring committee; BMl: Body mass index.

\section{Competing interests}

The authors declare that they have no competing interests.

\section{Authors' contributions}

TY, TH, TA, JS, HF, HC, TY, HT, RF, and AT conceived and coordinated the study, collected patients' data and participated in the statistical analysis. RY, MM, and AT participated in preparing and drafting the manuscript. All authors read and approved the final manuscript.

\section{Acknowledgement}

This study was supported in part by a Grant-in-Aid from the Kanagawa Health Fundation.

\section{Author details}

'Department of Gastrointestinal Surgery, Kanagawa Cancer Center, 1-1-2 Nakao, Asahi, 241-0815 Yokohama, Kanagawa, Japan. ²Department of Surgery, Yokohama City University, Yokohama, Japan. ${ }^{3}$ Department of Anesthesiology, Kanagawa Cancer Center, 1-1-2 Nakao, Asahi, 241-0815 Yokohama, Kanagawa, Japan. ${ }^{4}$ Department of Surgery, Teikyo University School of Medicine, 2-11-1 Kaga, 173-8605 Itabashi, Tokyo, Japan.

Received: 7 October 2013 Accepted: 2 July 2014

Published: 8 July 2014

\section{References}

1. Parkin DM, Bray F, Ferlay J, Pisani P: Global cancer statistics, 2002. CA Cancer J Clin 2005, 55:74-108

2. Bonenkamp JJ, Songun I, Hermans J, Sasako M, Welvaart K, Plukker JT, van Elk P, Obertop H, Gouma DJ, Taat CW, Lanschot J, Meyer S, Graaf PW, Meyenfeldt MF, Tilanus H: Randomised comparison of morbidity after D1 and D2 dissection for gastric cancer in 996 Dutch patients. Lancet 1995, 345:745-748.

3. Cuschieri A, Fayers P, Fielding J, Craven J, Bancewicz J, Joypaul V, Cook P. Postoperative morbidity and mortality after D1 and D2 resections for gastric cancer: preliminary results of the MRC randomised controlled surgical trial. The Surgical Cooperative Group. Lancet 1996, 347:995-999. 
4. Degiuli M, Sasako M, Calgaro M, Garino M, Rebecchi F, Mineccia M, Scaglione D, Andreone D, Ponti A, Calvo F: Morbidity and mortality after D1 and D2 gastrectomy for cancer: interim analysis of the Italian Gastric Cancer Study Group (IGCSG) randomised surgical trial. Eur J Surg Oncol 2004, 30:303-308.

5. Sano T, Sasako M, Yamamoto S, Nashimoto A, Kurita A, Hiratsuka M, Tsujinaka T, Kinoshita T, Arai K, Yamamura Y, Okajima K: Gastric cancer surgery: morbidity and mortality results from a prospective randomized controlled trial comparing D2 and extended para-aortic lymphadenectomy-Japan Clinical Oncology Group study 9501. J Clin Oncol 2004, 22:2767-2773.

6. Kim HH, Hyung WJ, Cho GS, Kim MC, Han SU, Kim W, Ryu SW, Lee HJ, Song KY: Morbidity and mortality of laparoscopic gastrectomy versus open gastrectomy for gastric cancer: an interim report-a phase III multicenter, prospective, randomized trial (KLASS Trial). Ann Surg 2010, 251:417-420.

7. Katai H, Sasako M, Fukuda H, Nakamura K, Hiki N, Saka M, Yamaue H, Yoshikawa T, Kojima K: Safety and feasibility of laparoscopy-assisted distal gastrectomy with suprapancreatic nodal dissection for clinical stage I gastric cancer: a multicenter phase II trial (JCOG 0703). Gastric Cancer 2010, 13:238-244.

8. Lassen K, Soop M, Nygren J, Cox PB, Hendry PO, Spies C, von Meyenfeldt MF, Fearon KC, Revhaug A, Norderval S, Ljungqvist O, Lobo DN, Dejong CH, Enhanced Recovery After Surgery (ERAS) Group: Consensus review of optimal perioperative care in colorectal surgery: Enhanced Recovery After Surgery (ERAS) Group recommendations. Arch Surg 2009, 144:961-969.

9. Varadhan KK, Neal KR, Dejong CH, Fearon KC, Ljungqvist O, Lobo DN: The enhanced recovery after surgery (ERAS) pathway for patients undergoing major elective open colorectal surgery: a meta-analysis of randomized controlled trials. Clin Nutr 2010, 29:434-440.

10. Spanjersberg WR, Reurings J, Keus F, van Laarhoven CJ: Fast track surgery versus conventional recovery strategies for colorectal surgery. Cochrane Database Syst Rev 2011, 2:CD007635.

11. Gustafsson UO, Scott MJ, Schwenk W, Demartines N, Roulin D, Francis N, McNaught CE, MacFie J, Liberman AS, Soop M, Hill A, Kennedy RH, Lobo DN, Fearon K, Ljungqvist O, Enhanced Recovery After Surgery Society: Guidelines for perioperative care in elective colonic surgery: Enhanced Recovery After Surgery (ERAS $\left.{ }^{\oplus}\right)$ Society recommendations. Clin Nutr 2012, 31:783-800.

12. Yamada T, Hayashi T, Cho H, Yoshikawa T, Taniguchi H, Fukushima R, Tsuburaya A: Usefulness of enhanced recovery after surgery protocol as compared with conventional perioperative care in gastric surgery. Gastric Cancer 2012, 15:34-41.

13. Wang $D$, Kong $Y$, Zhong B, Zhou $X$, Zhou $Y$ : Fast-track surgery improves postoperative recovery in patients with gastric cancer: a randomized comparison with conventional postoperative care. J Gastrointest Surg 2010, 14:620-627.

14. Chen Hu J, Xin Jiang L, Cai L, Tao Zheng H, Yuan Hu S, Bing Chen H, Chang Wu G, Fei Zhang Y, Chuan LZ: Preliminary experience of fast-track surgery combined with laparoscopy-assisted radical distal gastrectomy for gastric cancer. J Gastrointest Surg 2012, 16:1830-1839.

15. Liu XX, Jiang ZW, Wang ZM, Li JS: Multimodal optimization of surgical care shows beneficial outcome in gastrectomy surgery. J Parenter Enteral Nutr 2010, 34:313-321.

16. Grantcharov TP, Kehlet $\mathrm{H}$ : Laparoscopic gastric surgery in an enhanced recovery programme. Br J Surg 2010, 97:1547-1551.

17. Dorcaratto D, Grande L, Pera M: Enhanced Recovery in Gastrointestinal Surgery: Upper Gastrointestinal Surgery. Dig Surg 2013, 30:70-78.

18. Sakakshev BE: Enhanced Recovery after Surgery for Gastric Cancer. J Gastrointest Dig Syst 2013, S12:003. doi: 10.4172/2161-069X.S12-003.

19. Japanese Gastric Cancer Association: Japanese gastric cancer treatment guidelines 2010 (ver. 3). Gastric Cancer 2011, 14:113-123.

20. Dindo D, Demartines N, Clavien PA: Classification of surgical complications: a new proposal with evaluation in a cohort of 6336 patients and results of a survey. Ann Surg 2004, 240:205-213.

21. JSobin LH, Gospodarowicz MK, Witterkind CH: International Union Agains Cancer (UICC) TNM Classification of Malignant Tumors. 7th edition. Oxford, UK: Wiley-Black-well; 2009.

22. Hirao M, Tsujinaka T, Takeno A, Fujitani K, Kurata M: Patient-controlled dietary schedule improves clinical outcome after gastrectomy for gastric cancer. World J Surg 2005, 29:853-857.

23. Lassen $\mathrm{K}$, Dejong $\mathrm{CH}$, Ljungqvist $\mathrm{O}$, Fearon $\mathrm{K}$, Andersen J, Hannemann $\mathrm{P}$, von Meyenfeldt MF, Hausel J, Nygren J, Revhaug A: Nutritional support and oral intake after gastric resection in five northern European countries. Dig Surg 2005, 22:346-352.

24. Suehiro T, Matsumata T, Shikada Y, Sugimachi K: Accelerated rehabilitation with early postoperative oral feeding following gastrectomy. Hepatogastroenterology 2004, 51:1852-1855.

25. Jo DH, Jeong O, Sun JW, Jeong MR, Ryu SY, Park YK: Feasibility study of early oral intake after gastrectomy for gastric carcinoma. J Gastric Cancer 2011, 11:101-108.

26. Heslin MJ, Latkany L, Leung D, Brooks AD, Hochwald SN, Pisters PW, Shike M, Brennan MF: A prospective, randomized trial of early enteral feeding after resection of upper gastrointestinal malignancy. Ann Surg 1997, 226:567-577.

27. Lewis SJ, Andersen HK, Thomas S: Early enteral nutrition within $24 \mathrm{~h}$ of intestinal surgery versus later commencement of feeding: a systematic review and meta-analysis. J Gastrointest Surg 2009, 13:569-575.

doi:10.1186/1471-2482-14-41

Cite this article as: Yamada et al:: Feasibility of enhanced recovery after surgery in gastric surgery: a retrospective study. BMC Surgery 2014 14:41.

\section{Submit your next manuscript to BioMed Central and take full advantage of:}

- Convenient online submission

- Thorough peer review

- No space constraints or color figure charges

- Immediate publication on acceptance

- Inclusion in PubMed, CAS, Scopus and Google Scholar

- Research which is freely available for redistribution

Submit your manuscript at www.biomedcentral.com/submit
C) Biomed Central 